\title{
THE IMPACT OF DIGITAL COMMUNICATION TECHNOLOGY AS EDUCATIONAL TOOLS INTO PHYSICAL EDUCATION PROGRAMS: A LITERATURE REVIEW
}

\author{
By \\ Nabanita Das* \\ Sports Instructor, Basic Science and Humanities, University of Engineering and
} Management,Kolkata-700160,India

\begin{abstract}
Digital technology became an integral component of Physical Education and Sports Science curricula and Professions. The study aims at critically reviewing recently published scientific literature on the use of Digital Communication Technology in Physical Education with a view - (i) to identifying the potential contribution of the incorporation of digital communication technology as educational tools into Physical Education programs, (ii) to present a synthesis of the available empirical evidence on the educational effectiveness of digital communication technology in Physical Education, and (iii) to identify future research perspectives concerning the educational use of digital communication technology in Physical Education. After systematically searching online bibliographic databases, relevant articles, websites and journals were located and included in the study. The outcomes of the literature review are discussed in terms of their implications for future research, and can provide useful guidance to educators, practitioners and researchers in the areas of Health Education, Physical Education and Sports Sciences.
\end{abstract}

Keywords: Physical Education, Digital Communication, Educational Tools.

\section{INTRODUCTION}

Digital Communication Technology represents one of the most useful tools to enhance curriculum if used correctly. Technology has had a significant impact on students' outcomes when compared to traditional instruction. Furthermore, the Ministry of Education is laying much emphasis on integrating Digital Communication Technology in the teaching and learning process in secondary schools. As students perform exercises and skills in their Physical Education classes, Physical Education teachers can use technological tools and systems to quantify processes and results to help them learn more about themselves. [1] According to Green (2002), with the rapid developments in technology, Digital Communication Technology has made a significant impact on a number of Physical Education departments, and has the potential to enhance teaching and learning in Physical Education. [2]Cummings (2002) suggested that the pervasion of Digital Communication Technology in education is now impacting on Physical Education as much as on any other subjects. [3]

Despite increasing availability of digital technology, and growing research in this area, questions still remain amongst practitioners and researchers as to how we gain maximum benefit from the array of technology at our disposal. Casey, Goodyear and Armour (2016, p. 247) called for teachers to 'be brave' in spite of the challenges sometimes faced when trying to integrate technology into lessons with the intention of supporting and enhancing learning. [4]

\section{Purpose of the study:}

nabanita.das@uem.eduin 
The study aims at critically reviewing recently published scientific literature on the use of Digital Communication Technology in Physical Education with a view -(i) to identifying the potential contribution of the incorporation of digital communication technology as educational tools into Physical Education programs,(ii) to present a synthesis of the available empirical evidence on the educational effectiveness of digital communication technology in Physical Education, and(iii) to identify future research perspectives concerning the educational use of digital communication technology in Physical Education.

\section{LITERATURE REVIEWED}

Several research papers have been reviewed to reveal the treatment of the Digital Communication Technologies as an educational tools in the field of physical education.

Marina Papastergiou (2010),studied the enhancing Physical Education and Sport Science students' self-efficacy and attitudes regarding Information and Communication Technologies through a computer literacy course explored students' responses to the course, students' perceptions of the relevance of Information and Communication Technology for Physical Education and Sports Science professionals as well as eventual differences in the course's impact in relation to students' prior Information and Communication Technology experience. Participants were 89 Physical Education and Sports Science undergraduate students. Analysis revealed that the course significantly enhanced students' computer and Internet selfefficacy and their positive attitudes towards computers and the Internet, while significantly reducing their computer anxiety. The course was very wellreceived by the students, who were found to fully perceive the pervasiveness of
Information and Communication Technology in today's Physical Education and Sports Science professions, and who felt that they had developed valuable Information and Communication Technology skills. The course elicited positive responses regardless of students' prior Information and Communication Technology experience, although it had significantly more positive effects, in terms of computer self-efficacy, Internet self-efficacy and computer attitudes, with the students who were most in need of the course, namely those with low prior Information and Communication Technology experience. The findings are discussed in relation to training Physical Education and Sports Science students in ICT within academic settings. [5]

Marina Papastergiou (2009),in the study of exploring the potential of computer and video games for health and physical education reviewed that electronic games present many potential benefits as educational tools for Health and Physical Education, and that those games may improve young people's knowledge, skills, attitudes and behaviours in relation to health and physical exercise. Furthermore, the newly emerged physically interactive electronic games can potentially enhance young people's physical fitness, motor skills and motivation for physical exercise. The evidence to support the educational effectiveness of electronic games in Health and Physical Education is still rather limited, but the findings present a positive picture overall. [6]

Julia Sargent Taylor \& Francis(2018), in the study of the Digital technologies and learning in physical education: pedagogical cases, on expanding the knowledge about the ways in which digital technologies are being used by teachers to support and enhance young peoples' learning in physical education.[7] 
Penni, Tearle \&Gill Golder(2008), studied the use of ICT in the teaching and learning of physical education in compulsory education which involved the use of ICT within a one-year initial teacher education (ITE) course in the UK, specialising in physical education (PE). The study examined how the course, which operates in both university and school-based settings, endeavoured to support trainees' use of ICT in PE and then to identify areas where the programme could be improved in this respect. It also noted any specific training or resourcing needs which may be required to implement the recommended improvements. Findings have shown the high level of enthusiasm of the trainees, university tutors and school-based PE teachers for making more use of ICT in teaching and learning $\mathrm{PE}$, and their willingness to make changes in their practice to accommodate this. It also revealed a severe shortage of subject-specific professional development, and a widespread lack of understanding of needs, which was felt to have contributed to the lack of relevant ICT resources to which most school PE departments had access. [8]

Caseyet al. (2016), studied the relationship between pedagogy, technology and learning in health and physical education seeks to address two key questions: (1) how could a pedagogically driven approach to the use of DigiTech in health and physical education (HPE) benefit young people's learning and (2) what steps would required to develop new DigiTech pedagogies? In this paper, they argue that while we need to be aware of the risks, we also need to explore the opportunities for digital technologies (DigiTech) to shape HPE in new and positive ways. Specifically, a focus on pedagogy was largely missing from earlier discussions. In mapping the evidence-base on DigiTech against a three-dimensional categorisation of pedagogy - in the form of learners and learning, teachers and teaching, and knowledge and context. They concluded by arguing that for a 'profession-wide' debate to co-construct, trial and evaluate new ways in which we should - and should not - use DigiTech to optimise young people's learning in HPE. [9]

Casey \&Benjamin (2012), studied the use of digital technology to enhance student engagement in physical education, explored the use of video technology as an aid to student engagement in physical education. A comprehensive high school in Australia with disaffected students, the study used the New South Wales Quality Teaching Program as a basis for assessing the effectiveness of video technology in enhancing students' engagement in Physical Education lessons aimed at facilitating deeper understanding of throwing and catching. The results highlighted the effectiveness of video technology in enhancing engagement and subsequently suggested that such a degree of commitment helped students to develop understanding beyond technical replication and towards rational and reasoned student investigations around their learning. Additionally, it helped students to feel less marginalised and enabled them to be more engaged in their learning. [10]

Manuel Palao et al. (2012), tested the impact of video technology on student performance in physical education, was to assess the effectiveness of the use of video feedback on student learning in physical education, while also examining the teacher's responses to the innovation. Three classes from one Spanish high school participated in different conditions for learning hurdles in a track and field unit. These conditions compared the use of video feedback (either from the teacher or from peers) with no video. The 'video and teacher feedback' condition provided the most positive overall results, with statistically significant improvements in skill execution, technique, and knowledge learning, as well as the highest level of 
practice. Nonetheless, while acknowledging the utility of video feedback as an instructional tool, the teacher felt overwhelmed by the demands of the technology on both his time commitments and in terms of his own technology competencies. [11]

Weir \&Connor(2009), studied the use of digital video in physical education and stated the technical and operational aspects of a project investigating the role of digital video in physical education in 12 Irish schools over a period of two academic years. The project design involved a qualitative investigation into the use of digital video in three areas of physical education, namely teaching, learning and assessment. The group of physical education teachers who implemented the project received intensive training in the use of the technology initially and were also given additional training to meet the evolving needs of the project over its duration. The time demands placed on the team in terms of planning and preparation and post-production work were recorded. The motivational effect of the use of the technology on students was noted. The capacity of the technology to provide focused feedback on performances was examined through the reviewing of video clips of students' performances in physical education lessons. The use of digital video as an aid to both formative and summative assessment in physical education was also examined. Aspects of assessment for learning were used in providing a cohort of students with opportunities to set their own learning goals and evaluate their own learning while compiling electronic learning portfolios. A total of 31 such portfolios were collated. An examination of the use of digital video technology as a means of assessing practical performances was also undertaken. [12]

Papastergiou, Gerodimos and Antoniou(2011),tested the multimedia blogging in physical education: Effects on student knowledge and ICT self-efficacy displayed main idea behind this study was to explore the educational potential of multimedia blogging for academic disciplines such as Physical Education (PE) that are not heavily based on written discourse and where multiple representations are important in learning. A class blog was utilized as a means for PE students to reflect on and showcase their performances of four specific basketball skills, through creating multimedia posts on these skills and receiving comments from their instructors, peers and an external expert. The effectiveness of multimedia blogging was evaluated, in terms of the acquisition of knowledge of the specific basketball skills and the self-efficacy in Information and Communication Technologies (ICT), as compared to that of an equivalent multimedia website which lacked the blogging component. Students' responses to the blogging activity were also investigated. The sample were 70 undergraduate PE students who were assigned to two groups, one of which used the class blog (Group A, $N=35$ ) and the other one the website (Group B, $N=35$ ), both for 11 weeks. The study followed a pre-test/post-test experimental design, taking before and after measurements of each group through written questionnaires. Participation in the blogging activity did have a positive impact on students' ICT self-efficacy, given that Group A students exhibited significant gains in Internet selfefficacy as well as in multimedia processing and blogging self-efficacy, whereas those of Group B did not. Students' responses to the blogging activity were also positive. However, within both groups no significant increase was found in students' knowledge of the basketball skills. The implications of the findings for higher education and future research are discussed. [13]

Rodriguez Quijada(2015), investigated the information and Communication 
Technologies (ICT) in physical education. A theoretical review shed light on a very topical issue regarding the education of our youth. Studies show that ICTs are increasingly present in the field of physical education, but much remains to be done to make an effective use of them in education. [14]

Okposio O. Collins (2011), studied the Use of ICT in Teaching and Learning of Physical Education and has be summarized, in the following aspects: the needs for ICT, computer-motion analysis, internet, video analysis/conferencing, chatting and challenges. It is concluded that ICT use enormously improve teaching and learning of physical education and sport. [15]

\section{Digital Communication Technology as Educational Tools in Physical Education:}

The use of Digital communication Technology in Physical education makes the science of sport come to life by linking both physical and mental activity. It also helps to create full-fledged students who are able to concentrate better on both practical and theoretical work. Besides, it helps students to develop a better understanding of their own body parts and that of the human body in general. It also raises the profile of Physical Education within the establishment by making the subject not only interesting, but also attractive and effective. Furthermore, it brings enthusiasm and motivation for both Physical Education teachers and students.

Moreover, with the infusion of Digital Communication Technology in Physical Education, life-long learning can be supported through the collection of resources via the internet. According to Mike Rimmer, Head of Physical \& Social development at the Butters haw upper school in Bradford: "It's the excitement of learning in a different way."'[16]

\section{Computer:}

Computers-we used to produce documents, lesson plans, to convert scores management. It also involves video units PC heart rate monitor, remedy heart rate monitor and educational software. Computer also aid learning experiences when they are used for motion analysis. This involves using computer to examine the way learner moves and then determine ways in which this movement can be improved in a practical physical education class. This devise stresses how human motor abilities can be perfected and controlled. For example if you ask a softball pitcher how he/she throws a fastball, they may not be able to tell you. Motion analysis visually shows the rudiments and sequence of actions involved in arm, leg movements to enhance performance of skills. Video tape images are also transferred into computers. Special application software analyzes the images. It measures the exact angle at which the player s holding his or her arms and legs. The speed and efficiency of each movement is measured. When using images, the teachers, advantage consist in his possibility of making corrections as soon as pupils exercise is completed, which him to quickly progress and improves his learning. Other computer software such as the programmes Professional Evolution Soccer (PES) is used to play games. Learners play, identify appreciate the skills, rules and evaluate officiating of the game.

\section{Internet:}

Internet is a global system of interconnected computer networks that promotes free flow of information by pocket switching using the standardized internet protocol suit. It is a network that consist of millions of private and public academic business and government network of local global scope that are linked by copper wires, fibber-optic cables and wireless connections technologies. 
The internet provides various information resources and services which can be used by physical educators for teaching and learning. They include electronic mail, online chat, electronic transactions, and bulletin board, file transfer and file sharing, online newspapers, arid journals, online gaming and inter linked hyper text documents and other resources of the worldwide web. Physical education teachers share experiences with other professionals via the internet which are integrated into teaching lessons. Students explore new knowledge as they surf the web for assignments, chat with fellow students and play games online. The internet can be used to maximize the effectiveness their learning process of physical education. Students have the possibility to email their questions or comments concerning their questions concerning issues in health and audition fitness, physical education programmes, courses to their physical education teachers and academic staff. Internet is used access a machining list of professionals in the same area of study. A user sends an email message to like mailing list which is broadcast to other users for accessing current information. Examples are the sports philosophy and Questa lists.

\section{Pedometers:}

Theses apparatus also called step counters are mechanical sensors used to count steps and can easily be incorporated in Physical Education classes. They address motivation, assessment, and advocacy. Furthermore, they are portable and can be worn under the belt and be kept the whole day. Today, it can be said that the pedometer has become a recognized acceptable tool for measuring physical activity. Students can wear a pedometer and receive immediate and continuous feedback regarding their activity level (Beighle, Pangrazi andVincent, 2001).[17]Using pedometers at school can also demonstrate to parents that students are achieving a certain level of physical activity. By using the pedometers students will be able to see progress towards set goal and consequently will be more motivated in the classes.

\section{Heart Rate Monitors:}

Based completely on the student ability level and current level of fitness, the heart rate monitor makes learning more student centred. It also provides immediate feedback that can make students work harder (Bian, Partridge, King, Andon and Boyer, 2007). [18]As fitness level increases, student feel that their cardiovascular system is working and can set individualized goal to work more effectively. The Heart rate monitor will also provide real time data that will allow students to see how different exercises and activities affect the heart rate. Hence the heart rate monitor is a convenient apparatus that allows students to use up to date technology (Kirkwood andManon 2002).[19]Charts of maximum heart rate can be made for each student and track increase or decrease in their heart rate.

\section{Digital Video camera and visual analysis software:}

The use of the motion analysis system will surely enhance many areas of the physical education curriculum both in research and teaching. Using digital video camera has indeed simplified the collection of data. These results can then be imported to carry out interactive multimedia presentation to provide students with a better understanding of the importance of breaking skills into components and the consequences of subtle variation in techniques ( Ladda, Keating, Adam, Toscana, 2004).[20]The visual analysis software allows students to view captured movement and to analyse them. This particular technology can help teachers to control student's progress towards motor skills goals; provide feedback opportunities and assessing students 
learning (Fiorentino and Castelli, 2005).[21]

Using digital video camera to record pupils' performance in table tennis for example, can be a useful tool to help students improve their techniques. With the addition of motion analysis software, pupils have a professional supportive tool. For instance during a training session, a 'robot - pong', which is a special technological tool that distribute ping pong balls at varying direction and speed, is used to face a student. The Physical Education teacher can then use the Digital video camera to analyse the actions more closely. This is done with a view to improve the teaching and learning of table tennis. Digital video clips were used weekly to stress on proper and improper techniques and then the pupils were given the opportunity to evaluate their own techniques and the technique of others via the 'déjà vu' resource. In the Mauritian context, some state colleges which are actually working on a pilot project set up by the ministry of education are presenting candidates for the Cambridge $\mathrm{O}$ level Examination. Teachers involved in this project will have to make use of video cameras during the practical examination to record students' performance and then send them to Cambridge University. Each college involved in the pilot project have already received a laptop, an overhead projector and its respective screen. Digital video cameras and internet connection facilities will soon be available in these schools.

\section{Simulation and Games:}

Games such as Dance, Dance revolution, Fx cycles and Nintendo Wii Fit provide opportunities for students to be physically active and simultaneously enjoying themselves .These games can also be combined to other technologies to enhance the experience (Di Giorgio, 2004).[22]Concerning the Nintendo Wii Fit, work outs are done on a small balanced board that gamers stand on. The players receive instructions from screen and mimic the stretching and muscle building exercises. The Wii Fit tracking feature shows progress using the system. Therefore, it can be a valuable Physical Educational tool. However, teachers should not consider gaming system equivalent to traditional exercises. It should be considered as a supplement and a not a replacement of traditional exercises.

\section{DISCUSSION}

The findings from the synthesis of the published papers indicates the following overall trends:

Collaborative use of Digital Communication Technology (in pairs or small groups) is usually more effective than individual use, though some pupils, especially younger children, may need support in collaborating effectively.

$\square$ Digital Communication Technology can be used very effectively as a short but focused intervention to improve learning in Physical Education. Particularly when there is regular and frequent use (about three times a week) over the course of about a term (5 -10 weeks). Sustained use over a longer period is usually less effective at improving attainment.

Remedial and tutorial use of Digital Communication Technology can be particularly effective for lower attaining pupils or those with special educational needs or those from disadvantaged backgrounds in providing intensive support to enable them to catch up with their peers.

In researched interventions, Digital Communication Technology is best used as a supplement to normal teaching and learning in Physical Education, rather than as a replacement for it. This suggests some caution in the way in which Digital 
Communication Technological tools in Physical Education is adopted or embedded in schools.

\section{CONCLUSION}

Physical education essentially requires the performing physical activity. This is associated with the development of motor skill. Physical education within the school system requires time, facility space and interactive lesson plans. Digital Communication Technology provides access to information, compresses information, motivate learners, and connect learners to teachers and teacher to the colleagues. Nowadays, there are many available technological innovations that could be inserted into the physical education lesson. The visual physical education lesson is essentially based on the connected learning environment which uses technology that are networked in structure. Physical education should avail themselves of these Digital Communication Technology opportunities to make their lesson more real and dynamic.

\section{REFERENCES}

1. https://www.ukessays.com/essays/ed ucation/benefits-of-ict-in-physicaleducation-education-essay.php

2. https://www.ukessays.com/essays/ed ucation/benefits-of-ict-in-physicaleducation-education-essay.php

3. https://www.ukessays.com/essays/ed ucation/benefits-of-ict-in-physicaleducation-education-essay.php

4. Casey, Goodyear and Armour (2016). Digital Technologies and
Learning in Physical Education:

Pedagogical Case. Routledge

Publication November 142016. ISBN 9781138947290. Page no. 24, 276.

5. Marina Papastergiou (2010).Enhancing Physical Education and Sport Science students' self-efficacy and attitudes regarding Information and Communication

Technologies through a computer literacy course.

Computers \& Education, ISSN: ISSN-0360-1315, Volume 54, Issue 1, January 2010, Pages 298-308.

6. Marina Papastergiou (2009).Exploring the potential of computer and video games for health and physical education: A literature review.Computers \& Education, Volume 53, Issue 3, November 2009, Pages 603-622.

7. Julia Sargent Taylor \& Francis (2018).Digital Technologies and Learning in Physical Education: Pedagogical Cases. Sport, Education and Society, Volume 23, Issue 1, Pages 108-110.

8. Penni, Tearle \&Gill Golder (2008).The use of ICT in the teaching and learning of physical education in compulsory education: how do we prepare the workforce of the future?European Journal of 
Teacher education, Volume 31, Issue 1, 27 February 2008, Pages 55-72.

9. Ashley Casey, Victoria A. Goodyear \&Kathleen M. Armour (2016).Rethinking the Relationship between Pedagogy, Technology and Learning in Health and Physical Education. Sport, Education and Society, Volume 22,Issue 2,19 Sep 2016, Pages 288-304.

10. Dr. Ashley Casey \&Benjamin Jones (2012). Using digital technology to enhance student engagement in physical education.Asia-Pacific Journal of Health, Sport and Physical Education, Volume 2, Issue 2, 12 Mar 2012, Pages 51-66.

11. Jose Manuel Palao,Peter Andrew Hastie,Prudencia Guerrero Cruz \&Enrique Ortega(2012). The impact of video technology on student performance in physical education. Technology, Pedagogy and Education, Volume 24,Issue 1, 13 Aug 2013, Pages 51-63.

\section{Tony Weir \&Sean Connor} (2009).The use of digital video in physical education.Technology, Pedagogy and Education, Volume 18, 2009 - Issue 2, 06 Aug 2009, Pages 155-171.
13. MarinaPapastergiou, VassilisGerodimos, PanagiotisAntoniou(2011). Multimedia blogging in physical education: Effects on student knowledge and ICT self-efficacy. Computers \& Education, Volume 57, Issue 3, November 2011, Pages 1998-2010.

14. Rodríguez Quijada, Mateo (2015). Information and Communication Technologies (ICT) in physical education. A theoretical review. Sportis Scientific Technical Journal of School Sport, Physical Education and Psychomotricity, Volume 1, February 2015, Pages 75-86.

15. Okposio O. Collins (2011).The Use of ICT in Teaching and Learning of Physical Education Continental J. Education Research. Wilolud Journals, ISSN: 2141-4181, Volume 4, Issue 2, 2011, Pages 29-32.

16. THE ROLE OF ICT IN VARIOUS FIELDS OF PHYSICAL EDUCATION, International Journal of Emerging Technologies and Innovative Research, ISSN: 23495162, Vol.6, Issue 3, March-2019, Page 11-13.

17. Beighle, Aaron \&Pangrazi, Robert \& Vincent, Susan. (2001).

Pedometers, Physical Activity, and Accountability. Journal of Physical Education, Recreation \& Dance, Volume 72, Issue 9, Pages 
$16-$

19, DOI: 10.1080/07303084.2001.

10605861.

18. https://www.ukessays.com/essays/e

ducation/benefits-of-ict-in-

physical-education-education-

essay.php

19. https://writingapersuasiveessay124.bl

ogspot.com/2019/10/benefits-of-ict-

in-physical-education.html

20. Jose Manuel Palao, Peter Andrew

Hastie, Prudencia Guerrero

Cruz \&Enrique Ortega(2012),

UKEssays. (November 2018).

Benefits of ICT in Physical

Education Education Essay.

https://www.ukessays.com/essays/e

ducation/benefits-of-ict-in-physical-

education-education-

essay.php?vref $=1$

21. Tony Weir \&Sean Connor(2009),

UKEssays. (November 2018).

Benefits of ICT in Physical

Education Education

Essay.https://www.ukessays.com/es

says/education/benefits-of-ict-in-

physical-education-education-

essay.php?vref $=1$

22. Marina Papastergiou,

VassilisGerodimos, Panagiotis

Antoniou (2011), UKEssays.

(November 2018). Benefits of ICT

in Physical Education Education

Essay.

https://www.ukessays.com/essays/e

ducation/benefits-of-ict-in-physical-

education-education-

essay.php?vref $=1$ 